\title{
Teratoma Growing Syndrome: A Case Report and Litterature Revue
}

Dergamoun Hamza, Kadouri Youcef, Lakssir Jihad, Hachem Al Sayegh, Benslimane Lounis, Nouini Yassine

Service d'Urologie A, Centre Hospitalier Universitaire Ibn Sina

DOI: $10.36347 /$ sasjm.2020.v06i04.003

| Received: 19.03.2020 | Accepted: 27.03.2020 | Published: 07.04.2020

*Corresponding author: Dergamoun Hamza

\section{Abstract}

Teratoma growing syndrome is rare pathology in patients with non seminomatous germ cell tumors characterized by the increase in volume during chemotherapy of the tumor masses, whether retroperitoneal or at other metastatic sites. We report the case of a "growing teratoma syndrome" presenting as a retroperitoneal mass occurring in a patient previously treated by orchidectomy and chemotherapy for a non seminomatous mixed germ cell tumors of the testis without teratomatous component wich run fatal because of the lake of follow.

Keywords: Teratoma, chemotherapy, retroperitoneal masses.

Copyright @ 2020: This is an open-access article distributed under the terms of the Creative Commons Attribution license which permits unrestricted use, distribution, and reproduction in any medium for non-commercial use (NonCommercial, or CC-BY-NC) provided the original author and source are credited.

\section{INTRODUCTION}

The "growing teratoma syndrome" is a rare and often overlooked development of nonseminomatous germ cell tumors of the testicle, defined for the first time by Logothetis in 1982. It is a benign condition if it is taken care of early. It's exact pathogenesis is not clearly defined and its treatment is based on a surgical exercise of the mass when it is extirpable

\section{OBSERVATION}

17 years old young men presented in our hospital with abdominal pain and abdominal distention. He was treated in another hospital for a testis tumor and underwent left orchidectomie. The anatomopathological examination reveals a non seminomatous germ tumors reffering to a teratoma; he begins chemotherapy two months later.

Unfortunately and due to bad social and financial condition of the patient he was lost of vue and didn't make a adequate follow up. The examination of patients found a young man in bad general state; abdominal distention and a palpable abdominal mass.

The patient came in our departement with two topographies: The first one shows a large, poorlyvascularized tissue mass in the retroperitoneum, pushing outside the left kidney and with hydronephrosis. This mass is polylobed and measures $141312 \mathrm{~cm}$ (figure 1).The second tomography realized one year after showed a retroperitoneal mass currently measuring 14.1 X13.5 extended over $28.5 \mathrm{~cm}$ height (figure 2). Progression of the retroperitoneal tumor in the cranial cranial side.Tumor markers were normal.

The decision was to perform a surgical resection of the mass. The patient was then taken to the operating room.A median incision straddling the umbilicus was made; the surgical exploration finds a mass adhering to the meso also taking the vessels. The mass was at this stage not extirpable (figure 3).

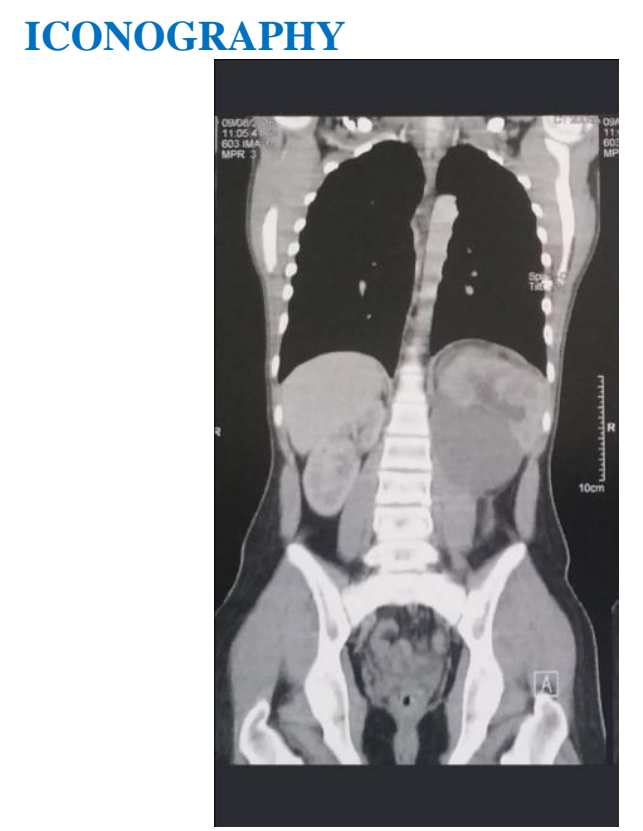

Fig-1: First tomography showing a polylobed mass measuring $14 \times 13 \times 12 \mathrm{~cm}$ 


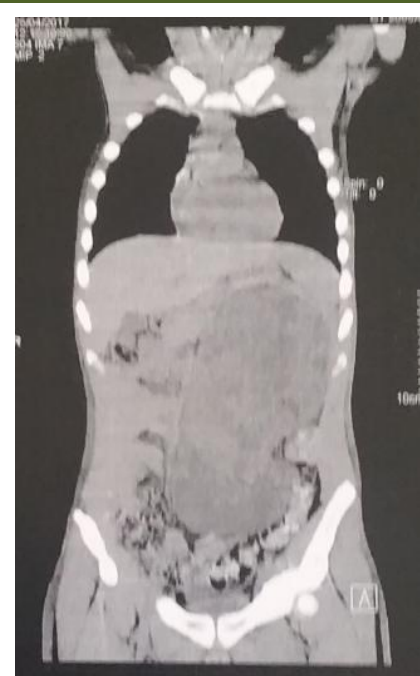

Fig-2: Second tomography showing a retroperitoneal mass currently measuring14.1x13.5 extended over $28.5 \mathrm{~cm}$ height

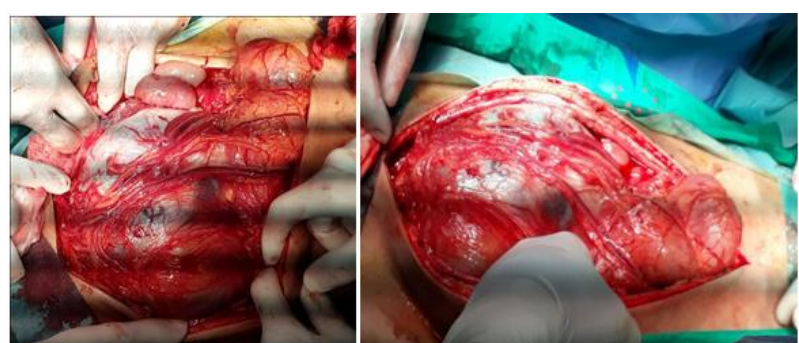

Fig-3: Per operative images

\section{DISCUSSION}

Teratoma growing syndrome, as defined for the first time by Logothetis in 1982, must satisfy three criteria: normalization of tumor markers, increase in volume of the tumor mass in progress or after chemotherapy, as well as the absence of active tissue within this teratoma[1].

Growing teratoma syndrome has a good prognosis when cured by complete surgical excision of the tumoral masses. Complications of this syndrome are due to masses compression. Malignant transformation is also possible.

The suspicion of this syndrome is due to the lumbar pain especially at patients seen late or lost of sight as reported by Andre [2].

Otherwise it's the tomography control during the chemotherapy which evokes a teratoma growing syndrome... Regular imaging of patients on follow up for malignant GCTs is the key to early diagnosis and treatment.

The pathogenesis of GTS is still unclear. The two most cited mechanisms are: selective chemoinduced destruction of germinal tumor histological components other than teratoma, the latter being chemo-resistant, and differentiation of malignant totipotent germinal cells into mature teratoma also induced by chemotherapy [3].
Surgical treatment is the reference treatment. It is classically more difficult due to volume or the connection of these tumor masses with the organs around, particularly in the case of a GTS occurring during follow-up with the difficulties common to secondary surgeries, in particular in their retroperitoneal localization [4].

The complete resection of GTS is mandatory, as ovarian GTS recurrence is reported with rates of 50 to $83 \%$ when incompletely resected versus 0 to $4 \%$ when complete resection is obtained [5].

The medical management of GTS with interferon alpha, bevacizumab and CDK (cyclindependent kinase) inhibitors is experimental.

Unfortunately, the delay in diagnosis was fatal for our patient making the surgical resection of the mass impossible. We wish to emphasize via this article despite the rarity of this pathology the necessity of the adequate follow-up and the discipline of the patients who if not respected makes the prognosis dark despite the begninity of the pathology.

\section{CONCLUSION}

Teratoma growing syndrome is a rare and benign condition in patient with non seminomatous germ cells, but the follow up of the patient is necessary, especially with iterative tomographies, it also need coordination between the urologist and the oncologist to have a good outcomes. Surgery is recommended but it remains difficult especially in the bulky teratomas.

\section{REFERENCES}

1. The growing teratoma syndrome. Logothetis CJ, Samuels ML, Trindade A, Johnson DE. Cancer. 1982 Oct 15;50(8):1629-35.

2. André F, Fizazi K, Culine S. The growing teratoma syndrome: results of therapy and long term followup of 33 patients. Eur J Cancer. 2000;36:1389-94.

3. Carr BI, Gilchrist KW, Carbone PP. The variable transformation in metastases from testicular germ cell tumors: the need for selective biopsy. J Urol. $1981 ; 126: 52-4$

4. Spiess PE, Kassouf W, Brown GA, Kamat AM, Liu P, Gomez JA, Tu SM, Tannir NM, Pisters LL. Surgical management of growing teratoma syndrome: the MD Anderson cancer center experience. The Journal of urology. 2007 Apr 1;177(4):1330-4.

5. Tangjitgamol S, Manusirivithaya S, Leelahakorn S, Thawaramara T, Suekwatana P, Sheanakul C. The growing teratoma syndrome: a case report and a review of the literature. International Journal of Gynecologic Cancer. 2006 Jan 1;16(Suppl 1):38490. 